\section{Response to Hartley et al. and Mullegama et al.}

To the Editor: We are pleased and would like to thank Hartley et al. ${ }^{1}$ and Mullegama et al. ${ }^{2}$ for their interest in our study. The main purpose of our study was to raise awareness in the genetics community about the real prevalence of fragile $\mathrm{X}$ syndrome $(\mathrm{FX})$ in males with nonsyndromic intellectual disability/learning delays (ID/LD) with or without autism spectrum disorder (ASD) and diagnostic yield of FX testing. In the past several years, we have observed an increased amount of FX testing requested by geneticists and other specialties such as primary care, neurology, and neurodevelopment. Moreover, the number of FX testing requests for females with ID/LD with or without ASD has increased as well. Our data from 2013 to 2015 revealed that FX testing had low diagnostic yield for males with ID/LD and males with ASD $(2.5 \%$ and $0 \%$, respectively), whereas chromosomal microarray provided higher diagnostic yields for both conditions. In "Fragile X Testing as a Second-Tier Test," Hartley et al. ${ }^{1}$ report similar findings: $2.4 \%$ diagnostic yield when FX testing was performed in a pediatric male population $(<19$ years old). In their letter, Mullegama et al. ${ }^{2}$ describe their experience over the past 15 years. They did not have positive FX testing giving $0 \%$ diagnostic yield when the test was performed in a pediatric male population (1-21 years old) with ID and/or ASD. In agreement with our observation, Hartley et al. ${ }^{1}$ report that all of their last five patients with positive FX testing had clinical presentation and family history strongly suggestive of FX.

In our institute, next-generation sequencing (NGS) genetic panels or whole-exome sequencing is requested as a secondtier test after negative chromosomal microarray. This is because, in our experience, NGS provided higher diagnostic yield than FX testing. Hartley et al. ${ }^{1}$ propose that NGS approaches should be considered before FX testing because these approaches provided higher diagnostic yield.

Additional findings such as severity of ID/LD, presence of major/multiple congenital anomalies, neurological symptoms, and family history may increase diagnostic yield. In a subgroup of patients with moderate or severe ID, the diagnostic yield of NGS was almost $30 \% .^{3}$ The diagnosis yield of exome sequencing in patients with ASD ranged from 3.1 to $28.6 \%$. In addition, a subgroup with complex ASD (ASD with additional findings including neurological symptoms, psychiatric problems, or multiple congenital anomalies) was more likely to receive positive results. ${ }^{4}$

In summary, we agree with Hartley et al. and Mullegama et al. that FX testing should be considered only in patients with clinical features and/or family history consistent with FX instead of routinely performing in patients with ID/LD and/or ASD.

NGS gene panels and whole-exome sequencing are valuable diagnostic tools and provide higher diagnostic yield than FX testing. However, both tests should be requested and interpreted by geneticists or health-care professionals with appropriate training. Appropriate pre- and posttest counseling must be offered. Certainly, these tests should be considered instead of single-gene tests in patients without features consistent with particular genetic syndromes.

Current American College of Medical Genetics and Genomics guidelines do not include NGS in the diagnostic evaluation tool and only recommend first-tier chromosomal microarray, FX testing, and second-tier single-gene analysis, including MECP2 and PTEN, for individuals with ASD. ${ }^{5}$

Over the past few years, genetic diagnostic technology has improved tremendously, not only in accuracy but also in turnaround time. Additionally, new genes related to LD/ID and/or ASD continue to be discovered. As a result, we think it is time that the recommendations be updated in accordance with new knowledge.

\section{DISCLOSURE}

The authors declare no conflict of interest.

Pranoot Tanpaiboon, $M D^{1}$ and

Kimberly A. Chapman, $M D, P h D^{1}$

${ }^{1}$ Division of Genetics and Metabolism, Children's National Health System, Washington, DC, USA. Correspondence: Kimberly A. Chapman (KChapman@childrensnational.org)

\section{REFERENCES}

1. Hartley T, Potter R, Badalato L, Smith AC, Jarinova O, Boycott KM. Fragile $X$ testing as a second-tier test. Genet Med. E-pub ahead of print 14 September, 2017.

2. Mullegama SV, Nguyen DC, Klein SD et al. Is it time to retire fragile $X$ testing as a first-tier test for developmental delay, intellectual disability, and autism spectrum disorder? Genet Med. E-pub ahead of print 21 September, 2017.

3. Hamdan FF, Srour M, Capo-Chichi JM et al. De novo mutations in moderate or severe intellectual disability. PLoS Genet 2014:10:e1004772.

4. Rossi M, El-Khechen D, Black MH et al. Outcomes of diagnostic exome sequencing in patients with diagnosed or suspected autism spectrum disorders. Pediatr Neurol 2017;70:34-43.

5. Schaefer GB; for the Professional Practice and Guidelines Committee. Clinical genetics evaluation in identifying the etiology of autism spectrum disorders: 2013 guideline revisions. Genet Med 2013;15:399-407.

Advance online publication 21 September 2017. doi:10.1038/gim.2017.148 